\title{
Pharmacological and genetic manipulations at the $\mu$-opioid receptor reveal arrestin-3 engagement limits analgesic tolerance and does not exacerbate respiratory depression
} in mice

\author{
Li He ${ }^{1,2}$, Sarah W. Gooding ${ }^{1}$, Elinor Lewis ${ }^{1}$, Lindsey C. Felth ${ }^{1}$, Anirudh Gaur ${ }^{1}$ and Jennifer L. Whistler ${ }^{1,2}$ \\ (c) The Author(s) 2021
}

Opioid drugs are widely used analgesics that activate the $\mathrm{G}$ protein-coupled $\mu$-opioid receptor, whose endogenous neuropeptide agonists, endorphins and enkephalins, are potent pain relievers. The therapeutic utility of opioid drugs is hindered by development of tolerance to the analgesic effects, requiring dose escalation for persistent pain control and leading to overdose and fatal respiratory distress. The prevailing hypothesis is that the intended analgesic effects of opioid drugs are mediated by $\mu$-opioid receptor signaling to $\mathrm{G}$ protein, while the side-effects of respiratory depression and analgesic tolerance are caused by engagement of the receptor with the arrestin-3 protein. Consequently, opioid drug development has focused exclusively on identifying agonists devoid of arrestin-3 engagement. Here, we challenge the prevailing hypothesis with a panel of six clinically relevant opioid drugs and mice of three distinct genotypes with varying abilities to promote morphine-mediated arrestin-3 engagement. With this genetic and pharmacological approach, we demonstrate that arrestin-3 recruitment does not impact respiratory depression, and effective arrestin-3 engagement reduces, rather than exacerbates, the development of analgesic tolerance. These studies suggest that future development of safer opioids should focus on identifying opioid ligands that recruit both $\mathrm{G}$ protein and arrestin-3, thereby mimicking the signaling profile of most endogenous $\mu$-opioid receptor agonists.

Neuropsychopharmacology (2021) 46:2241-2249; https://doi.org/10.1038/s41386-021-01054-x

\section{INTRODUCTION}

Opioids are highly effective analgesics and are essential for the treatment of severe pain [1]. However, prolonged use produces analgesic tolerance, necessitating dose escalation and increasing the risk of respiratory arrest [2]. Incidence of opioid overdose has climbed for decades and accounts for thousands of deaths by respiratory distress annually [3]. Recently, the charge to develop safer analgesic therapies has prioritized ameliorating the respiratory side-effects of opioid drugs.

Both the analgesic and respiratory effects of opioids are primarily mediated through the $\mu$-opioid receptor (MOR) $[4,5]$, a $G$ protein-coupled receptor (GPCR). GPCRs, when bound by agonist, activate heterotrimeric $G$ proteins. Arrestin-3 ( $\beta$-arrestin2) titrates $G$ protein signaling from GPCRs by promoting desensitization and endocytosis of receptors and scaffolds other signal effectors [6]. GPCR agonists can vary in their signaling bias: the relative engagement of $G$ protein versus arrestin-3 recruitment [7].

Opioid drugs vary in both their degree of signaling bias and effect/side-effect profile [8]. This has inspired hypotheses as to the role of signaling bias in their therapeutic utility. The predominant hypothesis that $G$ protein signaling promotes the analgesic effects of opioids, while arrestin-3 engagement is detrimental and causes the respiratory depressive side-effects, arose from the finding that mice lacking arrestin-3 (Arr-3 KO) displayed reduced respiratory depression in response to morphine (a MOR agonist) [9]. This finding led to a decade-long drive toward the development of MOR agonists devoid of arrestin-3 engagement with a goal to abolish respiratory depression while maintaining analgesia. However, most endogenous ligands efficiently engage arrestin-3 [10], and the small molecule opioid drug methadone, which also strongly engages arrestin-3, produces less tolerance and dependence than morphine [11], suggesting an alternative strategy for the development of safer opioids [12]. To clarify the role of arrestin-3 in the opioid side-effects of respiratory depression and tolerance, we examined six clinically relevant opioids with varying $\mathrm{G}$ protein biases at equi-analgesic doses. We also examined the respiratory side-effects of morphine in mice with varying abilities to recruit arrestin-3 to morphine-bound MOR: wild type (WT) mice, Arr-3 KO mice and a mouse expressing a mutant MOR (RMOR, for recycling MOR) that engages both $G$ protein and arrestin-3 in response to morphine [13]. RMOR's arrestin-3 engagement reduces the side-effects of opioid use that drive dose escalation, including tolerance [14] and abuse liability [15]. Here, we examine

\footnotetext{
${ }^{1}$ Center for Neuroscience, University of California-Davis, Davis, CA, USA. ${ }^{2}$ Department of Physiology and Membrane Biology, UC Davis School of Medicine, Davis, CA, USA. email: jlwhistler@ucdavis.edu
} 
respiratory side-effects in these mice and show that arrestin-3 engagement at MOR does not exacerbate respiratory depression and protects against the development of analgesic tolerance. This suggests the search for safer opioids should focus on identifying drugs that engage arrestin-3 to avoid the development of tolerance and lower abuse potential.

\section{METHODS \\ Drugs}

[D-Ala ${ }^{2}, \mathrm{~N}-\mathrm{Me}-\mathrm{Phe}^{4}, \mathrm{Gly}^{5}$-ol]-Enkephalin acetate salt (DAMGO), ( \pm )-methadone hydrochloride, fentanyl citrate, buprenorphine hydrochloride, oxycodone hydrochloride and naloxone hydrochloride dihydrate were purchased from Sigma (St. Louis, MO), morphine sulfate was purchased from Mallinckrodt (St. Louis, MO) and TRV130 hydrochloride was purchased from Adooq Biosciences LLC (Irvine, CA). The drugs were dissolved in physiological saline for in vivo studies except TRV130, which was dissolved in physiological saline with a final concentration of $1.5 \%$ DMSO for in vivo studies. All drugs were administered s.c. to mice in a volume of $10 \mathrm{ml} / \mathrm{kg}$. For in vitro pGlo studies, drugs were dissolved in deionized water or $1.5 \%$ DMSO to a concentration of $10 \mathrm{mM}$ and further diluted to obtain concentrations between $0.5 \mathrm{~nm}$ and $50 \mu \mathrm{M}$. No difference was found between $1.5 \%$ DMSO and deionized water. For in vitro arrestin-3 recruitment studies, all drugs were diluted in $1 \%$ DMSO with deionized water.

\section{Tail-flick assay}

Analgesia was measured using a cumulative dose-response in the radiant heat tail-flick assay (Tail-flick Analgesia Meter, Columbus Instrument. Columbus, $\mathrm{OH}$ ). The intensity of the light was adjusted so that baseline tailflick latencies ranged from 1.4 to $2.0 \mathrm{~s}$, and a cutoff time of three times the mean baseline latency was set to minimize damage to the tail. Each group consisted of at least 8 mice. Analgesia was tested $20 \mathrm{~min}$ after each s.c. administered dose, except with TRV130, which was tested after $10 \mathrm{~min}$. Three to four doses per mouse were used to establish the dose-response curve for each drug. Data are displayed as the "maximum possible effect" (\%MPE): $100^{*}[($ drug response time - baseline latency)/(cutoff time baseline latency)]. Cumulative dose-response curves were fit using GraphPad Prism, and the $A D_{50}$ values of the opioid drugs and their $95 \%$ confidence intervals were calculated. The $A D_{80}$ values for each drug were calculated from the same curves. To measure tolerance, mice were administered the drugs at the $A D_{80}$ for 6 days following a cumulative dose-response test on day 1 . On Day 8 , a second cumulative dose-response and $A D_{50}$ was determined and a fold shift in $A D_{50}$ from Day 1 to Day 8 was calculated.

\section{Withdrawal assessment}

WT C57BL/ 6 and RMOR mice were treated with morphine $(8 \mathrm{mg} / \mathrm{kg}$ and $1.5 \mathrm{mg} / \mathrm{kg}$, respectively) once daily for 6 days. Thirty minutes after the final drug injection, mice were injected with naloxone $(5 \mathrm{mg} / \mathrm{kg}$, s.c.) and observed for $20 \mathrm{~min}$ by an observer who was blind to experimental conditions. Standard withdrawal behaviors were used to score each mouse and included wet-dog shakes, jumps and paw tremors.

\section{Mouse plethysmography}

Respiration data was collected using a whole-body plethysmography system (Data Sciences International (DSI), St. Paul, MN). Mice were placed in the chambers after DSI airflow transducers were attached to each plethysmography chamber to maintain a constant flow rate. Each chamber was calibrated to its attached transducer before recording. Mice were habituated to the clear plexiglass chambers for 20 min per day for two days. On Day 3, mice were first habituated to the chambers for $10 \mathrm{~min}$. Respiratory parameters were then recorded for $10 \mathrm{~min}$ to establish a baseline before injection of vehicle or drugs and were collected for 80 min post drug injection at $10 \mathrm{~min}$ intervals. Opioid drugs were given to mice at their $A D_{80}$ analgesic dose to measure their respiratory depressive effects. To measure respiratory tolerance, mice were administered the $A D_{80}$ dose for 6 days following the first testing day. On Day 8, mice were given the $A D_{80}$, and their respiratory rates were measured as on Day 1. Both area under the curve (AUC) and maximum respiratory depression were calculated (minimum respiratory rate/baseline rate $\mathrm{x} 100$ for each mouse.)

\section{Arrestin-3 recruitment assay}

CHO-K1 OPRM1 PathHunter ${ }^{\circledR} \beta$-arrestin-2 cells (DiscoverX, Fremont, CA, USA) were seeded ( 2500 cells per well) in a low-volume, round-bottom, opaque 384-well plate. The next day, the cells were stimulated for $90 \mathrm{~min}$ with a series of MOR agonists $\left(3 \mathrm{nM}-30 \mu \mathrm{M}\right.$ ) in $1 \%$ DMSO (at $37^{\circ} \mathrm{C} / 5 \% \mathrm{CO}_{2}$.) Arrestin-3 recruitment was detected following a $60 \mathrm{~min}$ incubation period, according to the manufacturer's guidelines, with a PathHunter Detection reagent. Luminescence was measured using a Flexstation3 (Molecular Devices, San Jose, CA, USA). EC 50 and $E_{\max }$ values were determined with a nonlinear fit using GraphPad Prism 8 software (GraphPad Software, La Jolla, CA), and data were normalized and plotted as $\% E_{\max }$ produced by DAMGO. Each drug was tested in a minimum of three independent experiments with all doses in quadruplicate. Cells are tested monthly for mycoplasma.

\section{Statistics}

Respiratory effects (maximum respiratory depression and AUC) for each genotype at equi-analgesic doses were compared in both saline and morphine conditions using a two-way ANOVA with Tukey's multiple comparisons test. The effects of different morphine doses in 129SvJ mice were also compared to saline using a one-way ANOVA with Dunnett's multiple comparisons test. The respiratory effects of the opioid drug panel were assessed by comparing all drug conditions using a one-way ANOVA with Dunnett's multiple comparisons test. To assess respiratory tolerance, respiratory rates were normalized as \% baseline to account for baseline drift over time, and within-subjects comparisons for each drug on Day 1 and Day 8 were made using a two-way ANOVA with repeated measures and Sidak's multiple comparisons test. For in vitro assays, $\mathrm{IC}_{50}, \mathrm{EC}_{50}$ and $E_{\max }$ values for each drug were compared to the effect of DAMGO using a one-way ANOVA with Dunnett's multiple comparisons test. Arrestin-3 recruitment or CAMP inhibition were correlated with respiratory depression, analgesia or analgesic tolerance (calculated as fold shift in analgesic $A D_{50}$ from day 1 to day 8) using a simple linear regression.

\section{Mice}

Male C57BL/6 mice were purchased from Charles River Laboratories (Wilmington, MA), and male 129SvJ mice were purchased from The Jackson Laboratory (Sacramento, CA). Mice acclimated to the housing conditions for at least 5 days after arriving and were maintained under a standard 12/12-h light/dark cycle, with ambient temperature set at $20^{\circ} \mathrm{C}$ to $22^{\circ} \mathrm{C}$ and food and water ad libitum. Recycling MOR (RMOR) [11] mice have been bred congenic to C57BL/ 6 for $>30$ generations. Arrestin-3 (Beta arrestin-2) KO mice were generously provided by Dr. R. Lefkowitz (Duke University) and have been bred congenic to C57BL/ 6 for $>30$ generations. Mice aged 12-18 weeks were used and housed in groups of 3-4.

\section{Study approval}

All protocols were approved by the Institutional Animal Care and Use Committee at University of California Davis and are in accordance with the National Institutes of Health guidelines for care and use of laboratory animals

\section{RESULTS}

Arrestin-3 engagement improves morphine-induced analgesia and reduces morphine tolerance

We measured morphine-induced analgesia with a radiant heat tail-flick assay in three different mouse genotypes: WT, in which MOR poorly engages arrestin-3 in response to morphine [14], Arr-3 $\mathrm{KO}$ [16] and knock-in mice with a mutant MOR that robustly recruits arrestin-3 (RMOR) [13]. Using a cumulative dosing regimen, we found that WT and Arr-3 KO mice exhibit a similar analgesic dose-response to morphine $\left(A D_{50}\right.$ of 4.6 and $3.9 \mathrm{mg} / \mathrm{kg}$, respectively) (Fig. $1 \mathrm{~A}$ and Table S1). However, as previously reported [14], RMOR mice show enhanced morphine analgesia compared to WT $\left(A D_{50}: 1.0 \mathrm{mg} / \mathrm{kg}\right)$ (Fig. $1 \mathrm{~A}$ and Table $\mathrm{S} 1$ ). This suggests morphine analgesia is improved rather than impaired by engagement of arrestin-3 at MOR.

We next examined how arrestin-3 recruitment alters analgesic tolerance to morphine. The $A D_{80}$ dose of morphine for each genotype was calculated using the Day 1 dose-response (Fig. 1A) 


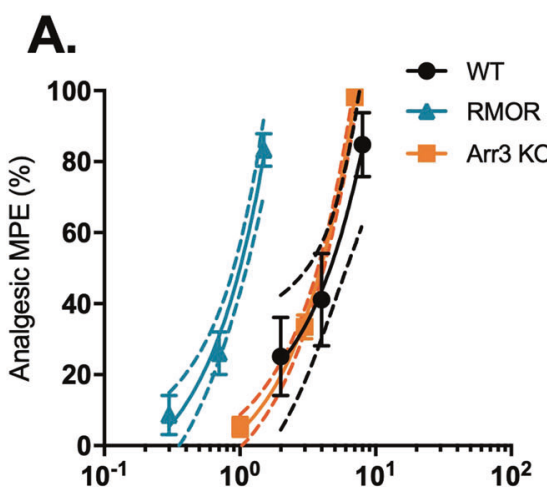

B.
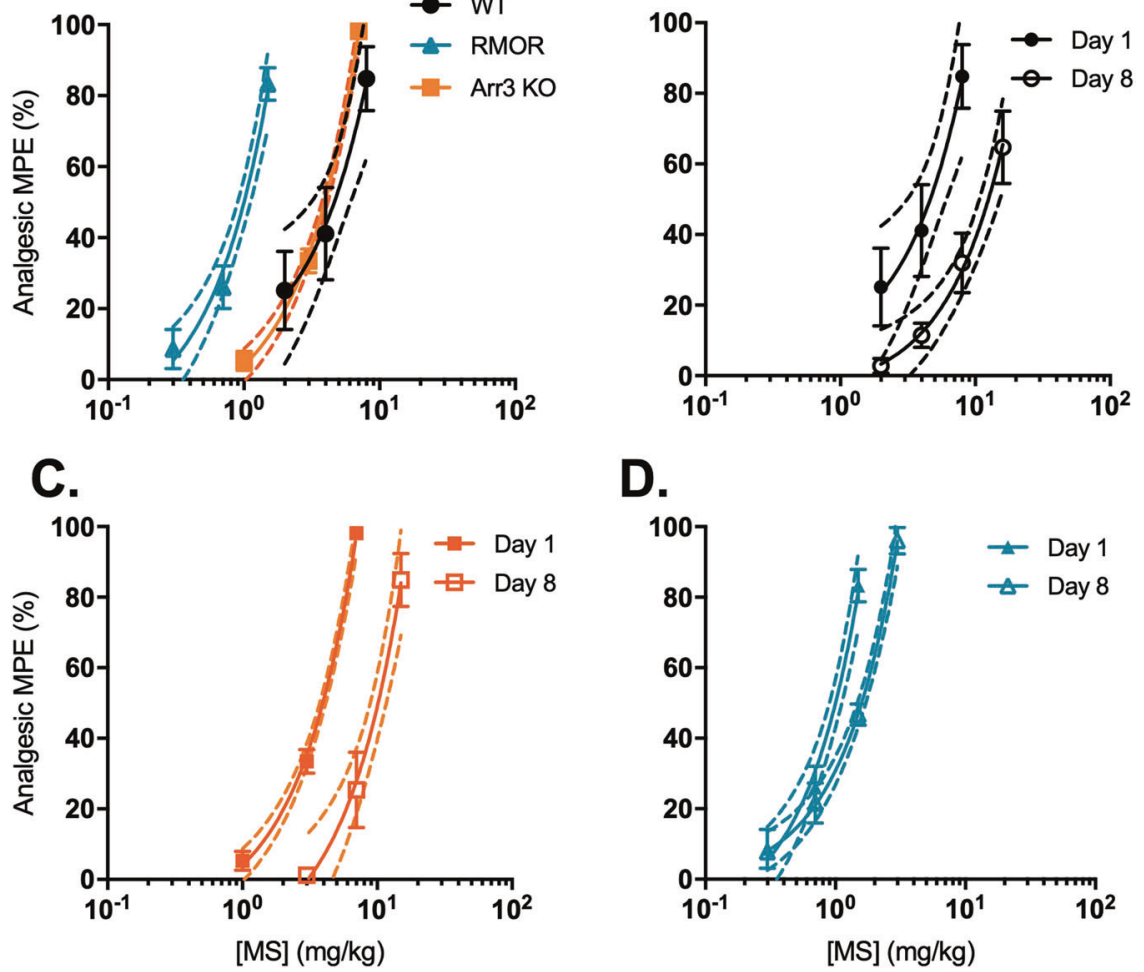

D.

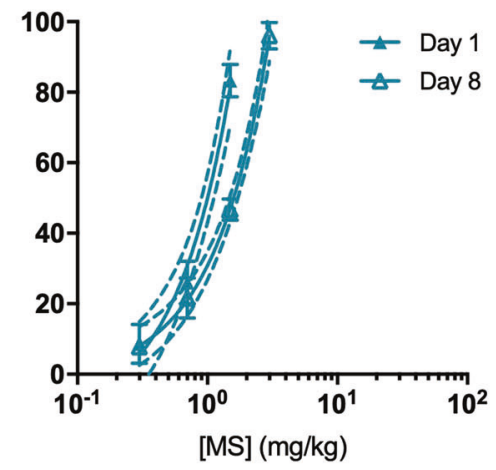

Fig. 1 Morphine analgesia and tolerance varies with arrestin-3 recruitment. A Acute morphine (MS) analgesia in WT mice ( $N=8$, black), Arr$3 \mathrm{KO}$ mice $(N=7$, orange) and RMOR mice $(N=8$, blue). B-D Tolerance: analgesic effects of MS on Day 1 (closed symbols) and Day 8 (open symbols) in (B) WT mice, (C) Arr-3 KO mice and (D) RMOR mice. Mice received an AD $_{80}$ dose of MS on days 2-7. RMORs showed reduced tolerance compared to WT and Arr-3 KO mice. Error bars represent SEM. Dotted lines represent $95 \%$ confidence intervals of the linear regression. Shift in $\mathrm{EC}_{50}$ from Day 1 to Day 8 shown in Table S1.

and was administered to the mice daily for 6 days $(8,6$, and $1.5 \mathrm{mg} / \mathrm{kg}$ in WT, Arr-3 KO and RMORs, respectively, s.c.). On Day 8, we performed a second dose-response and calculated the shift in morphine potency for each genotype (Fig. 1B, C, D and Table S1). Both WT and Arr-3 KO mice showed a rightward shift in their dose-response curves $\left(A D_{80}\right.$ fold shift 2.7 and 2.6, respectively), indicating development of analgesic tolerance as higher doses of morphine were required on Day 8 to achieve the same \%MPE (Fig. 1B, C and Table S1). RMOR mice exhibited reduced analgesic tolerance compared to WT (Fig. 1D and Table S1), expanding on previous reports [14] by showing no shift in the cumulative dose-response curve to morphine in RMOR mice.

\section{Arrestin-3 engagement does not exacerbate respiratory depression}

Previous studies report that loss of arrestin-3 engagement, either using Arr-3 KO mice [9] or novel, putative G-biased MOR agonists, reduces opioid-induced respiratory depression [17-19] although that has been recently challenged $[20,21]$. This implied that enhanced arrestin-3 recruitment, as occurs in RMOR mice, should increase respiratory depression. We assessed respiratory depression with whole-body plethysmography in WT, Arr-3 KO and $\mathrm{RMOR}$ mice in response to the $A D_{80}$ dose of morphine for each genotype. RMOR and WT mice showed comparable respiratory depression in response to equi-analgesic morphine (Fig. 2A, D and Table S1), indicating arrestin-3 engagement does not exacerbate respiratory depression. In contrast to the original report [9], Arr-3 $\mathrm{KO}$ also showed equivalent respiratory depression compared to WTs (Fig. 2B, D and Table S1), supporting recent reports from three independent laboratories [22].

This discrepancy in phenotype may be due to the mixed C57BL6/129SvJ background of the mice used in the original study $[9,16]$. The Arr-3 KO mice used in this study, although originally obtained from the same source, have been bred congenic to $\mathrm{C} 57 \mathrm{BL} / 6$ for $>30$ generations. 129SvJ mice are resistant to analgesic morphine tolerance $[23,24]$ and differ in several other physiological responses to morphine and other drugs of abuse [25-29]. We found that 129SvJ mice have a significantly lower baseline respiratory rate (254.7 \pm 9.4 breaths/ $\mathrm{min})$ than $\mathrm{C} 57 \mathrm{BL} / 6(441.5 \pm 10.2$ breaths $/ \mathrm{min})\left(F_{(3,66)}=25.41, P<\right.$ 0.0001 in a two-way ANOVA with Tukey's multiple comparisons test) and do not show morphine-induced respiratory depression at the equi-analgesic dose $(8 \mathrm{mg} / \mathrm{kg}$ ) of C57BL/6 (Fig. $2 \mathrm{C}$ and Table S2). We also measured respiratory depression in 129SvJ mice with $50 \mathrm{mg} / \mathrm{kg}$ morphine and found that it did significantly reduce respiratory rate (Ordinary one-way ANOVA, $F=20.79$, $P<0.0001$ ) (Fig. S1), suggesting that $129 \mathrm{SvJ}$ resistance to morphine's respiratory effects results from lower sensitivity than $\mathrm{C} 57 \mathrm{BL} / 6$, rather than a prohibitive effect from the lower baseline respiratory rate (Fig. S1). These results support the possibility that differences between historical and contemporary studies of Arr-3 KO mice could be explained by genetic background.

We then compared the abilities of five MOR agonist drugs (morphine, methadone, fentanyl, buprenorphine, and oxycodone), as well as the recently FDA-approved TRV130 (oliceridine) [19], to engage arrestin-3 using the DiscoverX Pathhunter assay. We found that all drugs tested exhibited lower $E_{\max }$ arrestin-3 recruitment than [D-Ala ${ }^{2}, \mathrm{~N}-\mathrm{Me}-\mathrm{Phe}^{4}$, Gly ${ }^{5}$-ol]-Enkephalin (DAMGO, a hydrolysis-resistant form of enkephalin), with methadone $(86.0 \%)$ and fentanyl (94.9\%) the most similar, followed by oxycodone and morphine $(78.9 \%$ and $33.8 \%$, respectively), while TRV130 and buprenorphine showed negligible arrestin-3 engagement (Fig. 3A and Table S3). 
A.
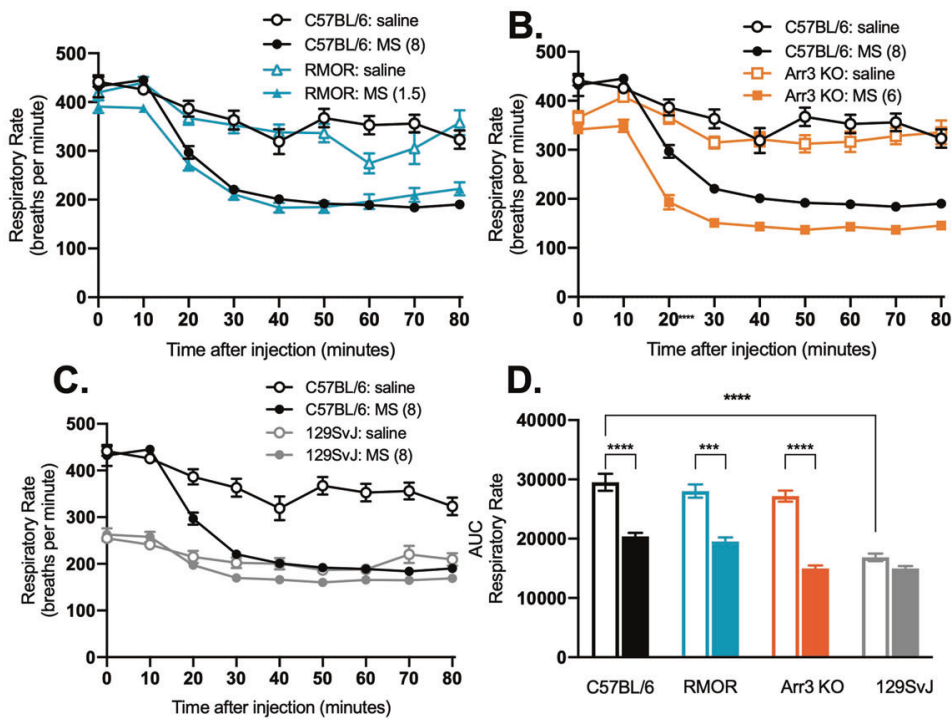

D.

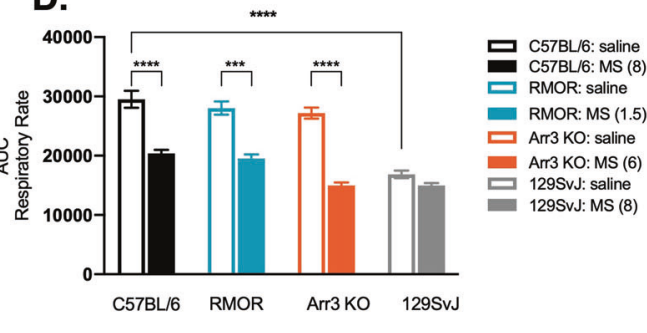

Fig. 2 Morphine-induced respiratory depression is independent of arrestin-3 recruitment and is dependent on genetic background. A Respiratory depression in C57BL/6 WT mice (black, $N=8)$ and RMOR mice $\left(N=8\right.$, blue) at the $\mathrm{AD}_{80}$ equi-analgesic dose determined in Fig. 1. B Respiratory depression in C57BL/6 WT mice (black, $N=8)$ and Arr-3 KO mice $\left(N=8\right.$, orange) at the $A D_{80}$ equi-analgesic dose determined in Fig. 1. C Respiratory depression in C57BL/6 WT mice $(N=8$, black) and 129SvJ WT mice $(N=8$, gray) given equivalent morphine. D Area under the curve for A-C (see Table S1). Error bars represent SEM.

The analgesic potency of each drug was determined in WT C57BL/6 mice using a cumulative dose-response protocol (Fig. 3B and Table S4). DAMGO was excluded because it cannot be administered systemically; it does not, however, produce analgesic tolerance when administered intrathecally [30]. We then administered the $A D_{80}$ dose of each drug and assessed degree of respiratory depression (Fig. 3D). We found that morphine, methadone, fentanyl, oxycodone and TRV130 did not significantly differ in their maximum respiratory depression in an ordinary oneway ANOVA with Tukey's multiple comparisons test (Figs. $3 \mathrm{C}$ and Table S5), but these drugs showed variable kinetic effects with regards to onset and duration of respiratory depression. The acute respiratory effect of buprenorphine administered at the $A D_{80}$ dose was not significantly different from saline (Fig. $3 C$ ). These results, together with those from Fig. 2, indicate no correlation (Figs. 5A and S2A) between magnitude of arrestin-3 recruitment and degree of respiratory depression.

\section{Correlation analysis of in vitro signaling properties and in vivo side-effects reveals an inverse correlation between arrestin-3 engagement and analgesic, but not respiratory tolerance}

Analgesic tolerance following repeated use of opioids necessitates dose escalation for persistent pain control [31]. We assessed analgesic tolerance to the $A D_{80}$ dose of each drug in our panel in WT mice with the protocol used for morphine in Fig. 1. Mice showed analgesic tolerance to all drugs except methadone (Fig. 4 left panels, Table S4). In a separate cohort, we assessed respiratory tolerance by measuring respiration in response to the $A D_{80}$ dose of each drug on Day 1 and Day 8 after daily treatment with the $\mathrm{AD}_{80}$ dose (Fig. 4 right panels, Table S4). Each drug's respiratory effect on Day 1 and Day 8 was compared, and the same dosing regimen that produced analgesic tolerance did not cause tolerance to the respiratory depressive effects of any of these drugs (no significance confirmed with two-way RM ANOVA with Sidak's multiple comparisons test).

We next correlated the in vitro arrestin-3 recruitment with the degree of analgesic tolerance to each drug (Figs. 5C and S2E). This analysis revealed a strong negative correlation between arrestin-3 recruitment and the development of analgesic tolerance $\left(R^{2}=\right.$ $0.829, P=0.012$ ). Drugs that efficiently recruit arrestin-3 at MOR promote low analgesic tolerance, and poor arrestin-3 recruiters cause the most analgesic tolerance. These results complement those in Fig. 1 showing that RMOR mice, in which arrestin-3 is engaged by morphine, are resistant to analgesic tolerance. These data suggest that arrestin- 3 recruitment improves the therapeutic utility for opioids by reducing analgesic tolerance so that dosage may remain low enough to mitigate respiratory risks.

\section{DISCUSSION}

The experiments herein show that $\mathrm{WT}$, Arr-3 KO and RMOR mice have similar respiratory responses to morphine (Fig. 2), and the promotion of arrestin-3 recruitment by six opioids at equi-analgesic doses is unrelated to their respiratory effects (Figs. 3, 5A and S2A). These results suggest that arrestin- 3 engagement is not a predictor of respiratory risk for opioids. We further demonstrate that arrestin-3 engagement in RMOR mice treated with morphine and WT mice treated with methadone reduces the development of analgesic tolerance, indicating a novel therapeutic strategy for opioid analgesic drug development that prioritizes engagement of arrestin-3. Our results complement recent studies from several groups reporting no difference in respiratory depression between WT and Arr-3 KO mice in response to morphine or fentanyl [22]. Another genetically modified mouse, which lacks phosphorylation of MOR (a phospho-null mouse) and consequently, arrestin-3 recruitment, also does not show improved respiratory depression [32]. Our finding that 129SvJ mice are less sensitive to morphine-induced respiratory depression suggests the likelihood that the early Arr-3 $\mathrm{KO}$ respiratory phenotype was affected by genetic background. Furthermore, a growing body of evidence suggests that $G$ protein mechanisms, such as GIRK channels [33-35] and $\mathrm{Ga}_{\mathrm{i}}$ signaling [36], are responsible for opioid-induced respiratory depression, and low $\mathrm{G}$ protein efficacy explains the reduced respiratory effect observed with the newer ultra-biased ligands [20]. All of this implicates G protein activity over arrestin-3 as the key player in opioid-induced respiratory depression, leaving no clear way to separate the analgesic and respiratory mechanisms of these drugs. Therefore, it 
A.

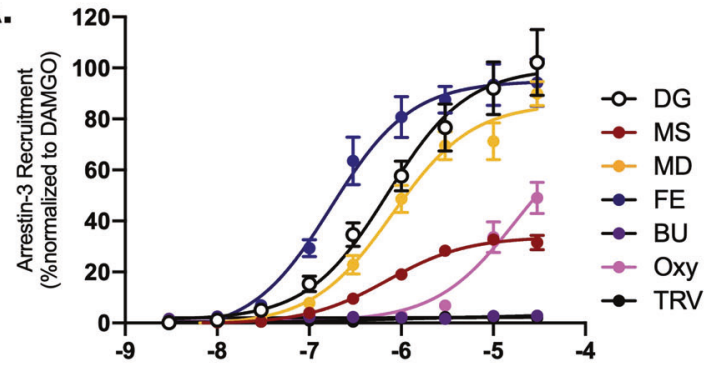

B.

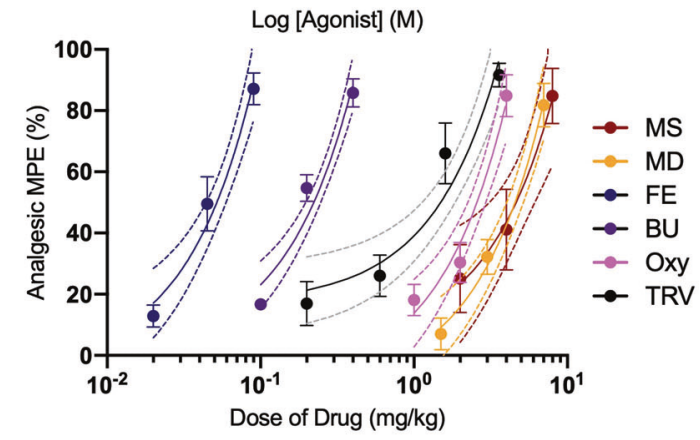

C.

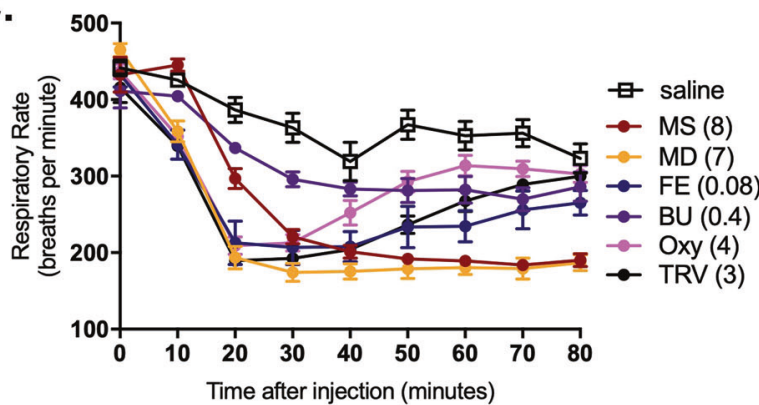

Fig. 3 Clinically important opioid drugs with variable arrestin-3 engagement produce respiratory depression at equi-analgesic doses. A Arrestin-3 recruitment in MOR PathHunter arrestin-3 cells in response to DAMGO (DG), morphine (MS), methadone (MD), buprenorphine (BU), fentanyl (FE), oxycodone (OXY) and TRV130 (TRV). Data points for TRV and BU overlap at several points. $\mathrm{EC}_{50}$ and $E_{\max }$ values are shown in Table S3. Data are mean $+/-$ SEM from 3 to 7 experiments, each performed in quadruplicate. B Analgesic dose-response to each drug in C57BL/6 WT mice $(N=8-10)$. C Respiratory depression to the $A D_{80}$ analgesic dose of each agonist $(N=8-10) . A D_{50}$ and Area Under the Curve (AUC) for $\mathbf{B}$ and C, respectively, are shown in Table S4. Peak (maximum respiratory depression) data for $\mathbf{B}$ is shown in Table S5. Maximums were compared to all other drugs with an ordinary one-way ANOVA and Tukey's multiple comparisons test (ns). Error bars represent SEM. Dotted lines represent confidence intervals calculated from the curve fit.

is critical to investigate mitigating strategies that consider factors beyond respiratory pathways, such as tolerance or abuse liability. It is also important to keep in mind that each of these drugs has its own unique profile with significant variability in half-life, intrinsic efficacy, affinity and off-target effects, all of which can complicate interpretation of in vivo data.

\section{Tolerance changes the therapeutic utility of morphine}

Analgesic tolerance to opioids drives dose escalation, which increases respiratory risk. Tolerance to the respiratory effects of opioids develops at a slower rate than analgesic tolerance, shrinking therapeutic utility, as the higher doses needed to maintain analgesia approach levels that risk respiratory distress [37-41]. Our results are consistent with these observations.
While arrestin-3 recruitment at MOR appears unrelated to respiratory depression (Figs. 5A, B and S2A), we found a strong negative correlation between the development of analgesic tolerance in vivo and arrestin-3 recruitment in vitro using a diverse panel of opioids. Of course, as mentioned above, these drugs vary in several properties beyond arrestin-3 recruitment, including affinity, intrinsic efficacy, bioavailability, half-life and offtarget effects. TRV130, for example, has a shorter lasting analgesic effect [19] and a more rapid return to normal breath rate than the longer acting drugs (so a smaller area under the curve), although acute respiratory depression in our hands is equivalent to that produced by morphine where the $\mathrm{ED}_{80}$ dose of each drug was chosen based on a cumulative dose-response for analgesia in the tail-flick assay. In this paradigm, $3 \mathrm{mg} / \mathrm{kg}$ of TRV130 was equivalent to $8 \mathrm{mg} / \mathrm{kg}$ of morphine for analgesia. This $3 \mathrm{mg} / \mathrm{kg}$ dose of TRV130 showed comparable respiratory depression to $8 \mathrm{mg} / \mathrm{kg}$ of morphine, which is similar to what was initially reported [19] but is higher than that shown in another recent report, which that measured analgesia with the hot plate assay [20]. More importantly, despite its short duration of action, TRV130 produced the greatest analgesic tolerance among the drugs we tested. For example, buprenorphine showed the lowest degree of respiratory depression, but its effect was more prolonged than that of TRV130, perhaps reflecting their differences in binding kinetics [42]. Note that, drugs with both long (morphine) and short (oxycodone) duration of action produced tolerance when given in doses equi-analgesic for their acute effect.

Differences in ligand efficacy for $G$ protein in particular, are likely critical to the interpretation of data comparing different drugs. Recently, it was shown that several putative $G$ proteinbiased ligands are partial agonists for $G$ protein signaling in nonamplified systems and/or where receptor number is limited, and therefore are not, in fact, G biased [20]. This includes TRV130, PZM21 and SR17018. The authors demonstrate that the low intrinsic efficacy of these more recent agonists is causal to their reduced respiratory depression (see refs. $[21,43]$ and references therein). For analgesic tolerance liability, ligand efficacy could likewise be an important property. However, even with the more sensitive efficacy assays employed in the above studies, methadone showed intrinsic efficacy comparable to DAMGO and higher than morphine and oxycodone. Nevertheless, methadone did not produce tolerance at equi-analgesic doses to morphine (Fig. 4B), suggesting that mechanisms other than intrinsic efficacy are at play.

To circumvent the variable of intrinsic efficacy (as well as different pharmacokinetics or other ligand properties), we used RMOR mice to show that tolerance to morphine is reduced by enhancing arrestin-3 engagement by the receptor without any increase in the respiratory depression (Fig. 2A). The RMOR receptor was created by substituting a portion of the cytoplasmic tail of MOR with that of DOR ( $\delta$-opioid receptor), creating a receptor that is a better substrate for $G$ protein coupled receptor kinases [44] without altering ligand affinity [14]. We cannot rule out that this substitution alters signaling in some way other than by increasing engagement of arrestin-3. However, the efficacies of morphine and DAMGO for $G$ protein signaling ex vivo are indistinguishable from the WT MOR in the VTA for both GIRK signaling and effects on GABA release [45]. One additional way to selectively examine the effects of arrestin-3 engagement versus efficacy on tolerance would be to examine the effects of methadone (which promotes arrestin-3 engagement and has $\mathrm{G}$ protein efficacy comparable to DAMGO [20]) in the phospho-null mice [32]. Furthermore, it would be interesting to examine the effects of SR17018 in the phosphonull mice. Grim et al. posit that the reduced tolerance to SR17018 is a function of poor arrestin-3 recruitment [46]. However, Gillis et al. [20] show that SR17018 is not G protein-biased but rather shows low efficacy for both $G$ and arrestin-3 (therefore "balanced"). If arrestin-3 recruitment reduces tolerance, we would 
A.

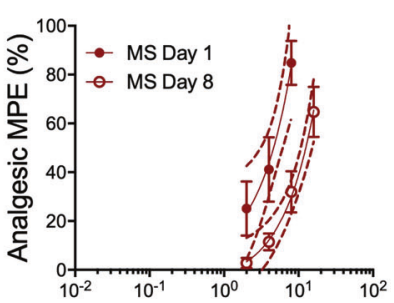

B.

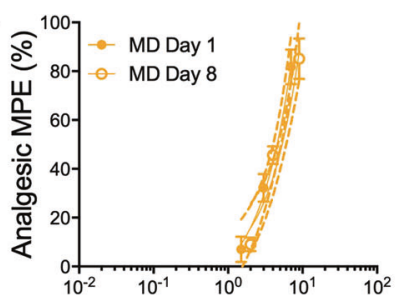

C.

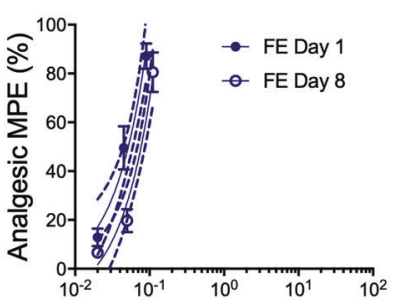

D.

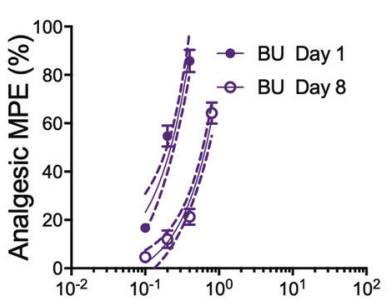

E.

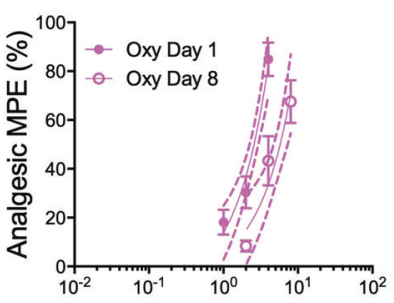

F.

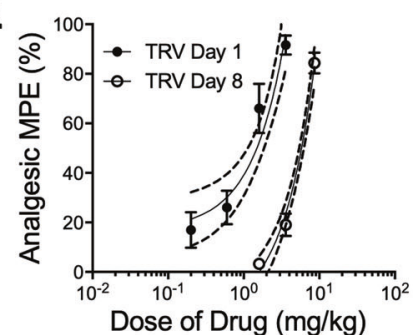

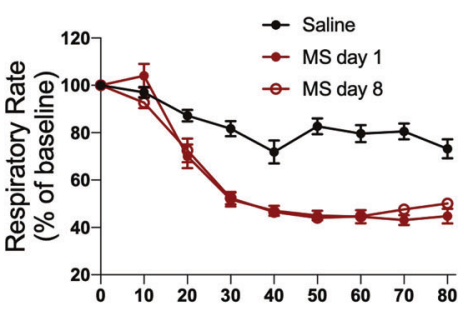
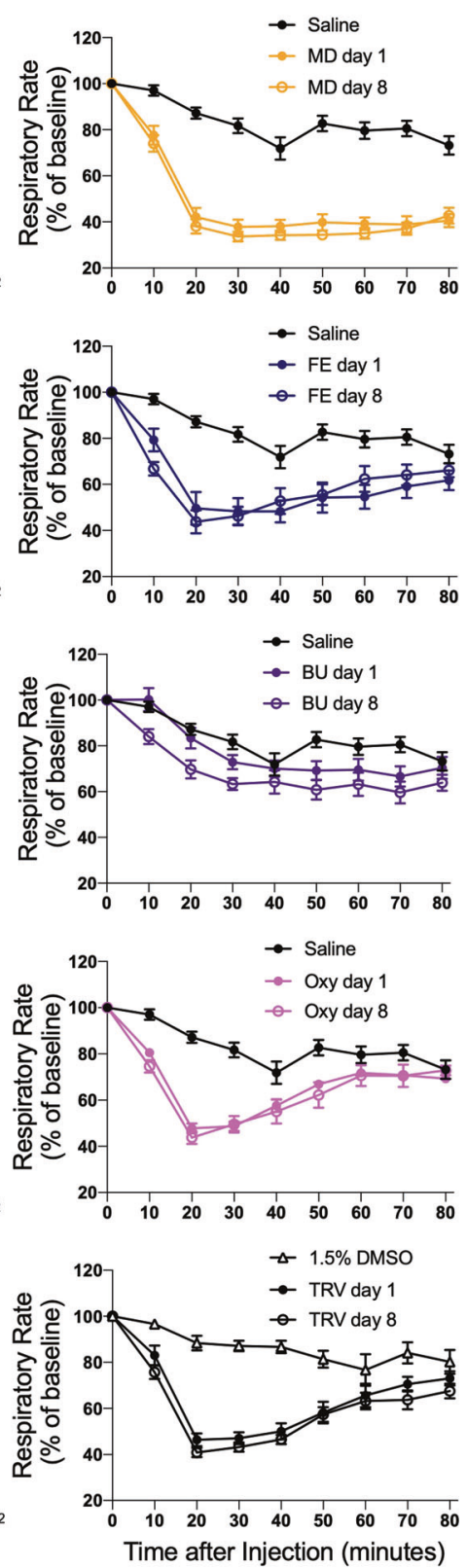

Fig. 4 Analgesic tolerance is dependent on degree of arrestin-3 recruitment. No respiratory tolerance develops to these drugs. (A-F, left panels). Analgesia to each drug (A-F left panels, $N=8$ per drug) was measured on day 1 (closed symbols) and day 8 (open symbols). Mice were given the analgesic $A_{80}$ dose of drug on days $2-7$. (A-F, right panels) The respiratory depressive effects of each drug $(N=8$ per drug) were measured on day 1 (closed symbols) and day 8 (open symbols). Mice were given the analgesic $\mathrm{AD}_{80}$ dose of drug on days $2-7$. Day 1 and 8 are shown as percent of baseline for each drug. $A D_{50}$ values for analgesia and area under the curve (AUC) for respiration on Day 1 and Day 8 are shown in Table S4. A morphine, B methadone, C fentanyl, D buprenorphine, E oxycodone, and F TRV130. All drugs, except methadone, produced significant analgesic tolerance. No drug produced respiratory tolerance. Error bars represent SEM. Dotted lines represent confidence intervals calculated from the curve fit. 

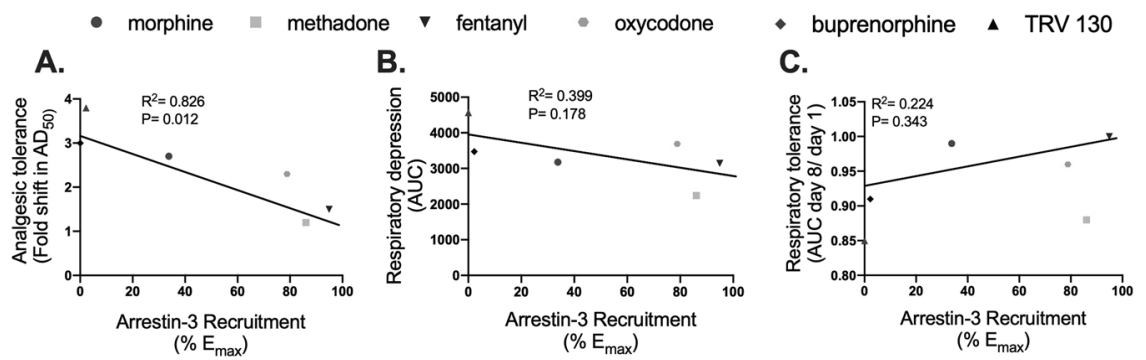

Fig. 5 Analgesic tolerance but not respiratory depression correlates with arrestin-3 recruitment. A Correlation analysis between the $E_{\max }$ of arrestin-3 recruitment (Fig. 3A) and analgesic tolerance to each drug (Fig. 4A-F left panels, Table S4). There is a significant inverse correlation where increased arrestin-3 engagement correlates with reduced analgesic tolerance. B, C Correlation analysis between the $E_{\text {max }}$ of arrestin-3 recruitment (Fig. $3 \mathrm{~A}$ ) and tolerance to the respiratory effects of each drug (Fig. 4A-F right panels, Table S4).

expect methadone and SR17018 to produce more tolerance in the phospho-null mice compared to WT mice. If arrestin-3 engagement produces tolerance, the phospho-null mice should show reduced tolerance. In our hands, MOR engagement of arrestin-3 in RMOR mice did not exacerbate respiratory side-effects and improved analgesic efficacy during prolonged treatment by preventing the development of analgesic tolerance. Our results suggest that agonists that engage both $\mathrm{G}$ protein and arrestin-3 have the potential to improve the therapeutic utility of opioids, maintaining analgesic potency through prolonged administration without increasing respiratory risk. It may be that optimizing both for "balanced" signaling and lower efficacy could greatly improve opioid safety.

\section{Arrestin-3 can influence tolerance through multiple mechanisms}

Enhanced arrestin-3 binding (RMOR mice) [14] and arrestin-3 recruitment by methadone [11] protect against analgesic tolerance, and endocytosis of MOR is associated with a reduction in analgesic tolerance $[47,48]$. Previous studies have also reported reduced morphine tolerance in Arr-3 KO mice [49] and phosphonull mice that lack arrestin-3 binding [32]. We found that Arr-3 KO mice had a small but not significant decrease in analgesic tolerance compared to WT, which could reflect a difference in analgesic assays between studies or the aforementioned differences in genetic background. We propose a model to reconcile reduced tolerance in these three different mouse models by explaining how either elimination or enhancement of arrestin-3 activity could decrease tolerance.

Both desensitization of the receptor on the cell membrane and homeostatic adaptations that oppose the MOR signaling cascade produce analgesic tolerance to opioids. Compared to endogenous ligands, morphine produces incomplete phosphorylation of receptor [50,51], poor arrestin-3 recruitment [52, 53], partial desensitization [54] and poor resensitization [55], especially following multiple drug exposures $[55,56]$. This rapid, partial and largely irreversible desensitization of MOR in response to morphine is likely reduced in mice lacking all MOR phosphorylation sites [32] or lacking arrestin-3 [16]. By extension, we would expect such mice to show enhanced analgesia to acute morphine. Rapid resensitization, as occurs with endorphins in WT mice or morphine in RMOR mice, would also be expected to enhance analgesia. In fact, Arr-3 KO, phospho-null and RMOR mice all exhibit enhanced acute morphine analgesia [14, 16, 32]. We hypothesize that partial, irreversible receptor desensitization plays a minor role in the development of analgesic tolerance, which is primarily driven by homeostatic adaptations downstream of the receptor that occur when $G$ protein signaling from MOR is not properly titrated by arrestin- 3 engagement and the cycle of desensitization and resensitization. This model predicts that both Arr-3 KO and phospho-null mice would show reduced morphine tolerance compared to WT (or to any drug that produced partial irreversible phosphorylation/desensitization). Also, more balanced agonists may cause increased tolerance in these strains as the absence of arrestin- 3 activity would promote the homeostatic adaptations that morphine produces in WT mice, a hypothesis that has not yet been tested. This model also predicts that RMOR mice would exhibit even less tolerance by preventing both partial desensitization and mitigating the homeostatic adaptations occurring downstream of the receptor $[45,57]$. This is completely consistent with our data in Fig. 1. By extension, agonists that properly titrate $G$ protein signal by promoting full phosphorylation of receptors, arrestin-3 engagement, receptor endocytosis and recycling would show excellent analgesia and reduced tolerance.

Arrestin-3 engagement may reduce abuse potential of opioids Few studies have addressed the role of arrestin-3 recruitment in abuse potential. Opioid abuse is frequently a consequence of dose escalation due to analgesic tolerance, but the abuse liability of opioids is exacerbated by physical dependence and withdrawal symptoms when the drug is removed. Previous reports show that disruption of arrestin-3, either genetic or pharmaceutical, has no effect on the development of morphine dependence $[32,49,58]$. In contrast, compared to WTs, RMOR mice show attenuated morphine dependence [14], indicated by reduced withdrawal behaviors after 8 days of morphine treatment (Fig. S3). RMOR mice also show reduced affective dependence, assessed by conditioned place aversion to naloxone after repeated morphine treatment [15].

While reward is a popular proxy for abuse liability, more study on the relationship between arrestin-3 engagement and opioid reward is necessary. While both RMORs [15] and Arr-3 KOs [59] show enhanced morphine conditioned place preference (CPP), RMOR mice, unlike WT, do not transition to compulsive drug seeking in self-administration paradigms or show reinstatement to drug seeking after extinction [15], demonstrating that reward is a flawed indicator of abuse potential. Furthermore, while both PZM21 and TRV130, which promote negligible arrestin-3 engagement, show reduced CPP compared to morphine [18, 58], TRV130 is comparable to other opioids in its promotion of self-administration, facilitation of intracranial self-stimulation and physical dependence $[58,60,61]$. The current evidence, therefore, favors a high abuse liability for agonists that do not engage arrestin-3, independent of their reward properties.

Here, we have demonstrated that MOR engagement with both $\mathrm{G}$ protein and arrestin-3 improves the therapeutic utility of opioids by reducing the development of analgesic tolerance without exacerbating respiratory effects. In combination with other data that suggests arrestin-3 recruitment can reduce dependence $[14,45,57]$, abuse liability and relapse [15], these findings indicate that new opioid development efforts should focus on identifying compounds that signal with a profile 
mimicking that of endogenous ligands, which engage both $G$ protein and arrestin-3.

\section{REFERENCES}

1. Rajagopal S, Kim J, Ahn S, Craig S, Lam CM, Gerard NP, et al. Beta-arrestin- but not G protein-mediated signaling by the "decoy" receptor CXCR7. Proc Natl Acad Sci USA. 2010;107:628-32.

2. Kunzler NM, Devin K, Babu K, Boyer EW. Opioid overdose, toxicity, and poisoning. The American Opioid Epidemic: from patient care to public health. Washington D.C.: American Psychiatric Association Publishing; 2018. www.aapi.org.

3. Scholl L, Seth P, Kariisa M, Wilson N, Baldwin G. Drug and opioid-involved overdose deaths-United States, 2013-2017. MMWR Morb Mortal Wkly Rep. 2018;67:1419-27.

4. Matthes HW, Maldonado R, Simonin F, Valverde O, Slowe S, Kitchen I, et al. Loss of morphine-induced analgesia, reward effect and withdrawal symptoms in mice lacking the mu-opioid-receptor gene. Nature. 1996;383:819-23.

5. Dahan A, Sarton E, Teppema L, Olievier C, Nieuwenhuijs D, Matthes HW, et al. Anesthetic potency and influence of morphine and sevoflurane on respiration in mu-opioid receptor knockout mice. Anesthesiology. 2001;94:824-32.

6. Shenoy SK, Lefkowitz RJ. beta-Arrestin-mediated receptor trafficking and signal transduction. Trends Pharm Sci. 2011;32:521-33.

7. Wootten D, Christopoulos A, Marti-Solano M, Babu MM, Sexton PM. Mechanisms of signalling and biased agonism in $\mathrm{G}$ protein-coupled receptors. Nat Rev Mol Cell Biol. 2018;19:638-53.

8. Conibear AE, Kelly E. A biased view of mu-opioid receptors? Mol Pharm. 2019;96:542-49.

9. Raehal KM, Walker JK, Bohn LM. Morphine side effects in beta-arrestin 2 knockout mice. J Pharm Exp Ther. 2005;314:1195-201.

10. Thompson GL, Lane JR, Coudrat T, Sexton PM, Christopoulos A, Canals M. Biased agonism of endogenous opioid peptides at the mu-opioid receptor. Mol Pharm. 2015;88:335-46.

11. Enquist J, Ferwerda M, Milan-Lobo L, Whistler JL. Chronic methadone treatment shows a better cost/benefit ratio than chronic morphine in mice. J Pharm Exp Ther. 2012;340:386-92.

12. Berger AC, Whistler JL. How to design an opioid drug that causes reduced tolerance and dependence. Ann Neurol. 2010;67:559-69.

13. Finn AK, Whistler JL. Endocytosis of the mu opioid receptor reduces tolerance and a cellular hallmark of opiate withdrawal. Neuron. 2001;32:829-39.

14. Kim JA, Bartlett S, He L, Nielsen CK, Chang AM, Kharazia V, et al. Morphineinduced receptor endocytosis in a novel knockin mouse reduces tolerance and dependence. Curr Biol. 2008;18:129-35.

15. Berger AC, Whistler JL. Morphine-induced mu opioid receptor trafficking enhances reward yet prevents compulsive drug use. EMBO Mol Med. 2011;3:385-97.

16. Bohn LM, Lefkowitz RJ, Gainetdinov RR, Peppel K, Caron MG, Lin FT. Enhanced morphine analgesia in mice lacking beta-arrestin 2. Science. 1999;286:2495-8.

17. Schmid CL, Kennedy NM, Ross NC, Lovell KM, Yue Z, Morgenweck J, et al. Bias factor and therapeutic window correlate to predict safer opioid analgesics. Cell. 2017;171:1165-75. e13

18. Manglik A, Lin H, Aryal DK, McCorvy JD, Dengler D, Corder G, et al. Structurebased discovery of opioid analgesics with reduced side effects. Nature. 2016;537:185-90.

19. DeWire SM, Yamashita DS, Rominger DH, Liu G, Cowan CL, Graczyk TM, et al. A G protein-biased ligand at the mu-opioid receptor is potently analgesic with reduced gastrointestinal and respiratory dysfunction compared with morphine. J Pharm Exp Ther. 2013;344:708-17.

20. Gillis A, Gondin AB, Kliewer A, Sanchez J, Lim HD, Alamein C, et al. Low intrinsic efficacy for $G$ protein activation can explain the improved side effect profiles of new opioid agonists. Sci Signal. 2020;13:1-18.

21. Gillis A, Kliewer A, Kelly E, Henderson G, Christie MJ, Schulz S, et al. Critical assessment of $\mathrm{g}$ protein-biased agonism at the mu-opioid receptor. Trends Pharm Sci. 2020;41:947-59.

22. Kliewer A, Gillis A, Hill R, Schmidel F, Bailey C, Kelly E, et al. Morphine-induced respiratory depression is independent of beta-arrestin2 signalling. $\mathrm{Br} J$ Pharmacol. 2020;177:2923-31.

23. Dockstader $\mathrm{CL}$, van der Kooy $\mathrm{D}$. Mouse strain differences in opiate reward learning are explained by differences in anxiety, not reward or learning. J Neurosci. 2001;21:9077-81.

24. Kolesnikov Y, Jain S, Wilson R, Pasternak GW. Lack of morphine and enkephalin tolerance in 129/SvEv mice: evidence for a NMDA receptor defect. J Pharm Exp Ther. 1998;284:455-9.

25. Homanics GE, Quinlan JJ, Firestone LL. Pharmacologic and behavioral responses of inbred C57BL/6J and strain 129/SvJ mouse lines. Pharm Biochem Behav. 1999;63:21-6.
26. Kuzmin A, Johansson B. Reinforcing and neurochemical effects of cocaine: differences among C57, DBA, and 129 mice. Pharm Biochem Behav. 2000;65:399-406.

27. Homanics GE, Le NQ, Kist F, Mihalek R, Hart AR, Quinlan JJ. Ethanol tolerance and withdrawal responses in $\mathrm{GABA}(\mathrm{A})$ receptor alpha 6 subunit null allele mice and in inbred C57BL/6J and strain 129/SvJ mice. Alcohol Clin Exp Res. 1998;22:259-65.

28. Miner LL. Cocaine reward and locomotor activity in C57BL/6J and 129/SvJ inbred mice and their F1 cross. Pharm Biochem Behav. 1997;58:25-30.

29. Schlussman SD, Ho A, Zhou Y, Curtis AE, Kreek MJ. Effects of "binge" pattern cocaine on stereotypy and locomotor activity in C57BL/6J and 129/J mice. Pharm Biochem Behav. 1998;60:593-9.

30. He L, Whistler JL. Chronic ethanol consumption in rats produces opioid antinociceptive tolerance through inhibition of mu opioid receptor endocytosis. PLoS ONE. 2011;6:e19372.

31. Colvin LA, Bull F, Hales TG. Perioperative opioid analgesia-when is enough too much? A review of opioid-induced tolerance and hyperalgesia. Lancet. 2019;393:1558-68.

32. Kliewer A, Schmiedel F, Sianati S, Bailey A, Bateman JT, Levitt ES, et al. Phosphorylation-deficient G-protein-biased mu-opioid receptors improve analgesia and diminish tolerance but worsen opioid side effects. Nat Commun. 2019;10:367.

33. Montandon G, Ren J, Victoria NC, Liu H, Wickman K, Greer JJ, et al. G-proteingated inwardly rectifying potassium channels modulate respiratory depression by opioids. Anesthesiology. 2016;124:641-50.

34. Levitt ES, Abdala AP, Paton JF, Bissonnette JM, Williams JT. mu opioid receptor activation hyperpolarizes respiratory-controlling Kolliker-Fuse neurons and suppresses post-inspiratory drive. J Physiol. 2015;593:4453-69.

35. Levitt ES, Williams JT. Desensitization and tolerance of Mu opioid receptors on pontine kolliker-fuse neurons. Mol Pharm. 2018;93:8-13.

36. Manzke T, Guenther U, Ponimaskin EG, Haller M, Dutschmann M, Schwarzacher S, et al. 5-HT4(a) receptors avert opioid-induced breathing depression without loss of analgesia. Science. 2003;301:226-9.

37. Athanasos P, Smith CS, White JM, Somogyi AA, Bochner F, Ling W. Methadone maintenance patients are cross-tolerant to the antinociceptive effects of very high plasma morphine concentrations. Pain. 2006;120:267-75.

38. Emery MJ, Groves CC, Kruse TN, Shi C, Terman GW. Ventilation and the response to hypercapnia after morphine in opioid-naive and opioid-tolerant rats. Anesthesiology. 2016;124:945-57.

39. Hill R, Lyndon A, Withey S, Roberts J, Kershaw Y, MacLachlan J, et al. Ethanol reversal of tolerance to the respiratory depressant effects of morphine. Neuropsychopharmacology. 2016;41:762-73.

40. Ling GS, Paul D, Simantov R, Pasternak GW. Differential development of acute tolerance to analgesia, respiratory depression, gastrointestinal transit and hormone release in a morphine infusion model. Life Sci. 1989;45:1627-36.

41. Paronis CA, Woods $\mathrm{JH}$. Ventilation in morphine-maintained rhesus monkeys. II: tolerance to the antinociceptive but not the ventilatory effects of morphine. J Pharm Exp Ther. 1997;282:355-62.

42. Pedersen MF, Wrobel TM, Marcher-Rorsted E, Pedersen DS, Moller TC, Gabriele F, et al. Biased agonism of clinically approved mu-opioid receptor agonists and TRV130 is not controlled by binding and signaling kinetics. Neuropharmacology. 2020;166:107718.

43. Gillis A, Sreenivasan V, Christie MJ. Intrinsic efficacy of opioid ligands and its importance for apparent bias, operational analysis, and therapeutic window. Mol Pharm. 2020;98:410-24.

44. Whistler JL, Chuang HH, Chu P, Jan LY, von Zastrow M. Functional dissociation of mu opioid receptor signaling and endocytosis: implications for the biology of opiate tolerance and addiction. Neuron. 1999;23:737-46.

45. Madhavan A, He L, Stuber GD, Bonci A, Whistler JL. mu-Opioid receptor endocytosis prevents adaptations in ventral tegmental area GABA transmission induced during naloxone-precipitated morphine withdrawal. J Neurosci. 2010;30:3276-86.

46. Grim TW, Schmid CL, Stahl EL, Pantouli F, Ho JH, Acevedo-Canabal A, et al. A G protein signaling-biased agonist at the mu-opioid receptor reverses morphine tolerance while preventing morphine withdrawal. Neuropsychopharmacology. 2020;45:416-25.

47. Zollner C, Mousa SA, Fischer O, Rittner HL, Shaqura M, Brack A, et al. Chronic morphine use does not induce peripheral tolerance in a rat model of inflammatory pain. J Clin Invest. 2008;118:1065-73.

48. Chao PK, Chang HF, Ou LC, Chuang JY, Lee PT, Chang WT, et al. Convallatoxin enhance the ligand-induced mu-opioid receptor endocytosis and attenuate morphine antinociceptive tolerance in mice. Sci Rep. 2019;9:2405.

49. Bohn LM, Gainetdinov RR, Lin FT, Lefkowitz RJ, Caron MG. Mu-opioid receptor desensitization by beta-arrestin- 2 determines morphine tolerance but not dependence. Nature. 2000;408:720-3. 
50. Just S, Illing S, Trester-Zedlitz M, Lau EK, Kotowski SJ, Miess E, et al. Differentiation of opioid drug effects by hierarchical multi-site phosphorylation. Mol Pharm. 2013;83:633-9.

51. Doll C, Konietzko J, Poll F, Koch T, Hollt V, Schulz S. Agonist-selective patterns of micro-opioid receptor phosphorylation revealed by phosphosite-specific antibodies. Br J Pharm. 2011;164:298-307.

52. Zhang J, Ferguson SS, Barak LS, Bodduluri SR, Laporte SA, Law PY, et al. Role for G protein-coupled receptor kinase in agonist-specific regulation of mu-opioid receptor responsiveness. Proc Natl Acad Sci USA. 1998;95:7157-62.

53. Whistler JL, von Zastrow M. Morphine-activated opioid receptors elude desensitization by beta-arrestin. Proc Natl Acad Sci USA. 1998;95:9914-9.

54. Williams JT, Ingram SL, Henderson G, Chavkin C, von Zastrow M, Schulz S, et al. Regulation of mu-opioid receptors: desensitization, phosphorylation, internalization, and tolerance. Pharm Rev. 2013;65:223-54.

55. Dang VC, Williams JT. Chronic morphine treatment reduces recovery from opioid desensitization. J Neurosci. 2004;24:7699-706.

56. Dang VC, Williams JT. Morphine-Induced mu-opioid receptor desensitization. Mol Pharm. 2005;68:1127-32.

57. He L, Kim JA, Whistler JL. Biomarkers of morphine tolerance and dependence are prevented by morphine-induced endocytosis of a mutant mu-opioid receptor. FASEB J. 2009;23:4327-34.

58. Liang DY, Li WW, Nwaneshiudu C, Irvine KA, Clark JD. Pharmacological characters of oliceridine, a mu-opioid receptor g-protein-biased ligand in mice. Anesth Analg. 2019;129:1414-21.

59. Bohn LM, Gainetdinov RR, Sotnikova TD, Medvedev IO, Lefkowitz RJ, Dykstra LA, et al. Enhanced rewarding properties of morphine, but not cocaine, in beta (arrestin)-2 knock-out mice. J Neurosci. 2003;23:10265-73.

60. Altarifi AA, David B, Muchhala KH, Blough BE, Akbarali $H$, Negus SS. Effects of acute and repeated treatment with the biased mu opioid receptor agonist TRV130 (oliceridine) on measures of antinociception, gastrointestinal function and abuse liability in rodents. J Psychopharmacol. 2017;31:730-39.

61. Austin Zamarripa C, Edwards SR, Qureshi HN, Yi JN, Blough BE, Freeman KB. The G-protein biased mu-opioid agonist, TRV130, produces reinforcing and antinociceptive effects that are comparable to oxycodone in rats. Drug Alcohol Depend. 2018;192:158-62.

\section{ACKNOWLEDGEMENTS}

We thank Dr. Robert Lefkowitz of Duke University for providing Arr-3 KO mice. We thank all members of the Whistler Lab for their valuable input.

\section{AUTHOR CONTRIBUTIONS}

Project was conceived by JLW and LH. LH, SWG, and LCF conducted in vivo experiments. SWG, LCF, and AG conducted in vitro experiments. $L H, S W G, L C F$, and EL conducted data analysis and statistics. SWG, EL, LCF, and LH generated figures. All authors contributed to writing and editing the manuscript.

\section{FUNDING AND DISCLOSURE}

This work was funded by the National Institutes of Drug Abuse of the National Institutes of Health under award numbers R01DA019958 (JLW), R01DA037963 (JLW) and F31DA051116 (SWG). Research was also supported by the National Institute of Mental Health of the National Institutes of Health under Award Number T32MH112507 (SWG and AG). Research was also supported by funds provided to JLW by the State of California through the University of California, Davis. The content is solely the responsibility of the authors and does not necessarily represent the official views of the National Institutes of Health or the University of California. The authors declare no competing interests.

\section{ADDITIONAL INFORMATION}

Supplementary information The online version contains supplementary material available at https://doi.org/10.1038/s41386-021-01054-x.

Correspondence and requests for materials should be addressed to J.L.W.

Reprints and permission information is available at http://www.nature.com/ reprints

Publisher's note Springer Nature remains neutral with regard to jurisdictional claims in published maps and institutional affiliations. Attribution 4.0 International License, which permits use, sharing, adaptation, distribution and reproduction in any medium or format, as long as you give appropriate credit to the original author(s) and the source, provide a link to the Creative Commons license, and indicate if changes were made. The images or other third party material in this article are included in the article's Creative Commons license, unless indicated otherwise in a credit line to the material. If material is not included in the article's Creative Commons license and your intended use is not permitted by statutory regulation or exceeds the permitted use, you will need to obtain permission directly from the copyright holder. To view a copy of this license, visit http://creativecommons. org/licenses/by/4.0/.

(c) The Author(s) 2021 